5. Crow, T.J. Relative efficacy of pimozide and lithium in psychosis. Paper read at the Fourth Bi-ennial Winter Workshop on Schizophrenia. Badgastein 24 29 January 1988.

6. Sautter, F.S., Garver, D. Familial differences in lithium responsive versus lithium nonresponsive psychoses. J Psychiatr Res 1982, 139: 1281-1285.

7. Vaillant, G.E. The natural history of the remitting schizophrenias. Am J Psychiatr 1963, 120: 367-376.

\section{Angiodysplasia: current concepts}

Sir,

Professor Hemingway should be congratulated on her excellent review of angiodysplasia. ${ }^{1}$ Reference is made to the possible aetiological role of aortic valvular stenosis in this condition. The incidence of this association is said to be between 15 and $25 \%$ in cases of angiodysplasia. ${ }^{2}$

In her review of the treatment options Professor Hemingway fails to mention aortic valve replacement. This has been shown to stem recurrent intestinal haemorrhage which in the long term would otherwise have necessitated segmental bowel resection. Colonoscopic evidence of angiodysplasia regression has also been reported following aortic valve replacement. ${ }^{2}$ Local electrocoagulation or photocoagulation may be necessary prior to aortic surgery since peroperative heparinization is essential. However, since the introduction of biosynthetic valves long term anticoagulation is not necessary.

I suggest that in patients with significant aortic stenosis and associated angiodysplasia the primary treatment of
8. Vaillant, G.E. Prospective prediction of schizophrenic remission. Arch Gen Psychiatr 1964, 39: 509-518.

9. Darwin, C.R. The Origin of Species. Republished J. M. Dent \& Sons, London, 1972, pp. 57-58.

10. Sheldon, P. R. Parallel gradualistic evolution of Ordovician trilobites. Nature 1987, 330: 561-563.

choice is valve replacement. Why perform two operations when one may cure both problems?

T.J. Christmas Department of Surgical Studies, The Middlesex Hospital, Mortimer Street, London WIN 8AA, UK.

\section{References}

1. Hemingway, A.P. Angiodysplasia: current concepts. Postgrad Med J 1988, 64: 259-263.

2. Cappell, M.S. \& Lebwohl, O. Cessation of recurrent bleeding from gastrointestinal angiodysplasias after aortic valve replacement. Ann Int Med 1986, 105: 54-57. 